\title{
ANÁLISE ACÚSTICA E ÍNDICE DE ESTIMULABILIDADE NOS SONS LÍQUIDOS DO PORTUGUÊS BRASILEIRO
}

\author{
Acoustic analysis and stimulability index for Brazilian Portuguese \\ liquid sounds
}

Haydée Fiszbein Wertzner ${ }^{(1)}$, Luciana de Oliveira Pagan-Neves ${ }^{(2)}$, Márcia Mathias de Castro ${ }^{(3)}$

\begin{abstract}
RESUMO
Objetivo: descrever as características acústicas obtidas por meio da análise acústica (AA) e do índice de estimulabilidade (IE) das líquidas [1]; [r]; [K]. Métodos: foram analisadas as produções de fala coletadas através da imitação de sílabas de dois sujeitos gemelares de 11:6 anos apresentando os processos de simplificação de líquidas e simplificação do encontro consonantal. As produções foram analisadas acusticamente e por meio do teste de estimulabilidade. Resultados: os dois sujeitos produziram adequadamente o som [1]. O sujeito 1 não foi estimulável para o [r], tendo substituídoo pelo [1] independentemente da vogal subseqüente. O sujeito 2 foi estimulável ao som [r] e o produziu de forma correta em apenas uma imitação quando acompanhado da vogal /a/. A AA permitiu verificar que o som [1] foi produzido de maneiras diferentes quando emitido de maneira adequada $e$ quando no lugar do som [r]. Os dois sujeitos foram estimuláveis para o [K]. A AA das produções entre o som $[K]$ acompanhado da vogal /a/ e da vogal / $u$ / apresentou diferença estatisticamente significante. A vogal /i/ mostrou-se o contexto menos facilitador para o sujeito 2. Conclusão: o emprego conjunto desses dois procedimentos mostrou-se eficaz na identificação de alterações acústico-articulatórias fornecendo parâmetros facilitadores para a aquisição de um determinado som, seja ele um parâmetro motor ou acústico.
\end{abstract}

DESCRITORES: Transtornos da Linguagem; Desenvolvimento Infantil; Linguagem Infantil; Patologia da Fala e Linguagem

\section{INTRODUÇÃO}

A aquisição e o desenvolvimento da fala e da linguagem, bem como suas alterações, são alvos de estudos há muito tempo. Apesar disso, diversos aspectos relacionados ao tema ainda não são explicáveis. Vários even-

(1) Fonoaudióloga; Professora Associada Livre Docente do curso de Fonoaudiologia da Faculdade de Medicina da Universidade de São Paulo.

(2) Fonoaudióloga; Centro de Docência e Pesquisa em Fisioterapia, Fonoaudiologia e Terapia Ocupacional da Universidade de São Paulo; Doutoranda pela Faculdade de Filosofia Letras e Ciências Humanas da Universidade de São Paulo.

(3) Fonoaudióloga; Centro de Docência e Pesquisa em Fisioterapia, Fonoaudiologia e Terapia Ocupacional da Universidade de São Paulo; Doutoranda em Ciências da Reabilitação pela Faculdade de Medicina da Universidade de São Paulo. tos acontecem ao mesmo tempo e a criança precisa coordená-los de forma a produzir som, caracterizá-lo por meio dos movimentos dos articuladores e associá-los ao código fonológico de sua língua.

Em relação ao aspecto fonológico da linguagem, é no decorrer de seu desenvolvimento que a criança adquire gradativamente o domínio dos sons da fala tanto no que diz respeito à sua percepção e produção como no que se refere à compreensão das regras lingüísticas que regem sua utilização numa determinada língua ${ }^{1}$.

Em geral, tanto para o português brasileiro como para o inglês norte-americano, a literatura descreve que os últimos sons a serem adquiridos, por possuírem um domínio complexo durante o desenvolvimento da fala, são as líquidas laterais e vibrantes. Alguns desses autores salientam ainda que antes dos 3 anos de idade a criança já adquiriu a maioria dos sons da fala, com exceção da lateral alveolar [1] e da vibrante alveolar [r] que são adquiridas um pouco mais tarde, por volta de 4 anos ${ }^{2-8}$. 
Assim como acontece nas crianças com desenvolvimento típico ou normal, nota-se também que nas crianças com diagnóstico de transtorno fonológico, estes são os sons mais comumente alterados ${ }^{8-11}$.

A intervenção fonoaudiológica buscando a melhora na produção desses sons é bastante difícil, o que tem conduzido pesquisadores da área a utilizar medidas diagnósticas mais objetivas tais como a análise acústica e o índice de estimulabilidade. Tais medidas pretendem traçar correlatos entre a produção do som que está sendo emitido e o gesto articulatório executado no momento da produção, fornecendo ao clinico dados que ajudam na condução do processo terapêutico.

A fonética acústica procura caracterizar de maneira objetiva a onda sonora vocal desde sua saída do trato vocal até sua chegada no ouvido do ouvinte. Os sons da fala podem, então, ser descritos em termos articulatórios, baseados na postura da língua e em termos acústicos propriamente ditos tais como os formantes e suas transições ${ }^{12-15}$.

A análise acústica oferece condições para que seja estabelecida uma classificação mais ampla dos sons da voz e da fala, principalmente quando comparada à fonética articulatória, justamente por tratar-se de uma classificação geral para todas as línguas ${ }^{16}$.

O falante é capaz de manipular as características acústicas dos sons que emite, tais como padrão de freqüência e duração, numa tentativa de otimizar sua comunicação conferindo a ela um maior grau de inteligibilidade ${ }^{17}$.

As mudanças que podem ser observadas no espectrograma obtido a partir da análise dos formantes da fala refletem, de uma forma simplista, as mudanças de posição que ocorrem durante a movimentação dos lábios e da língua, de abertura e fechamento de mandíbula e das mudanças de posição da laringe durante a fala.

Para as vogais, exaustivamente estudadas no inglês norte-americano, existe uma relação direta entre as freqüências formantes e o gesto articulatório. Essa relação pode ser estendida para todas as vogais de outras línguas por tratar-se de uma produção bastante uniforme, com o trato vocal aberto e sem constrições formadas à passagem do ar. Alguns autores descrevem esta relação como sendo o $\mathrm{F} 1$ relacionado com a altura da língua e o F2 com o avanço da língua dentro da cavidade oral. Desta forma, quando o F1 está mais baixo pode-se concluir que a língua está mais alta e quando o F2 estiver também mais baixo, indica que a língua assumiu uma posição mais posterior dentro da cavidade oral ${ }^{13,15,18,19}$.

Entretanto, estas correlações ainda não são claras para as consoantes devido à grande variabilidade encontrada durante a sua produção intra e inter falantes. Nem mesmo para as líquidas, que apresentam características vocálicas em sua formação acústica, estas conexões não aparecem de forma tão clara como para a produção de vogais. Isto acontece porque durante a produção das consoantes o trato vocal sofre modificações criando constrições (obstáculos) resistentes à passagem do ar criando novas regiões de ressonância que são responsáveis pela caracterização de cada uma das consoantes existentes na língua.

A partir dos dados acústicos apresentados, uma medida que pode auxiliar a pesquisa na busca de correlações acústico-articulatórias é o índice de estimulabilidade que pode ser analisado em conjunto com a análise acústica com o objetivo de medir e explorar as possibilidades de produção do sujeito durante o processo de avaliação fonoaudiológica. A busca de uma análise conjunta se faz essencial e de grande ajuda para o clínico uma vez que muitos sons possuem posições articulatórias bastante próximas o que dificulta sua inteligibilidade quando somente $o$ padrão articulatório, ou o acústico, é considerado ${ }^{17}$.

A estimulabilidade é definida como a habilidade que o sujeito possui em modificar imediatamente os erros na produção de fala quando apresentado um modelo articulatório desse som. Se o desempenho da criança for melhor na tarefa imitativa do que na emissão espontânea, ela é classificada como sendo estimulável para o som testado ${ }^{20}$.

Para que o sujeito seja caracterizado como estimulável para um determinado som, é imprescindível que haja a integridade, em algum grau, do aspecto sensorial, do processamento lingüístico e da produção motora ${ }^{21}$.

A estimulabilidade é verificada para cada som que o sujeito não foi capaz de emitir corretamente durante a avaliação fonológica. Esse é um procedimento clínico para determinar se a criança é hábil em revisar o erro na fala quando são dadas pistas facilitadoras ${ }^{21}$.

Nos últimos anos registra-se uma tendência em quantificar a estimulabilidade para um determinado som, sendo os critérios para essa determinação bastante variados na literatura ${ }^{20,22-27}$.

A estimulabilidade é apontada como um fator que auxilia no prognóstico da intervenção no transtorno fonológico. Associada a essa questão, há a indicação que os sons estimuláveis podem ser adicionados ao inventário fonético da criança sem que sejam especificamente tratados ${ }^{20,21,27-30}$.

Alguns padrões fonológicos atípicos para uma determinada idade podem ter explicações sensoriais ou motoras. Os gestos articulatórios são representações abstratas do movimento e, se esses gestos são produzidos de diversas maneiras, o sujeito não se torna capaz de desenvolver os ajustes necessários para produzir o som alvo de forma correta. Desta maneira, quando a criança não tem o controle neuromuscular necessário para produzir os sons, ela 
adota estratégias de aproximação que podem ser identificadas como substituições e/ou distorções ${ }^{31,32}$.

Dessa maneira, o objetivo desta pesquisa foi descrever as características obtidas por meio da análise acústica (AA) e do índice de estimulabilidade (IE) das líquidas [1]; [r]; $[\Lambda]$ buscando traçar correlatos entre as medidas acústicas e os resultados obtidos na aplicação da prova do IE, além de verificar a validade desses instrumentos como formas diagnósticas complementares na identificação de alterações fonológicas.

\section{MÉTODOS}

Foram sujeitos deste estudo dois pré-adolescentes gemelares do sexo masculino com idade de 11:6 anos. Ambos foram provenientes do Laboratório de Investigação Fonoaudiológica em Fonologia (LIF Fonologia) do Departamento de Fisioterapia, Fonoaudiologia e Terapia Ocupacional da Faculdade de Medicina da Universidade de São Paulo.

Os sujeitos foram avaliados utilizando-se as provas de Fonologia do ABFW Teste de Linguagem Infantil ${ }^{33}$, a partir das quais foi dado o diagnóstico fonoaudiológico de Transtorno Fonológico. O critério de inclusão para participação na pesquisa foi de que os dois sujeitos apresentassem durante a avaliação fonológica os processos de simplificação de líquidas (SL) e simplificação do encontro consonantal (SEC). No processo SL está incluída tanto a omissão como a substituição de qualquer uma das três liquidas e, no SEC, a omissão ou substituição da liquida. Na Figura 1 , são apresentados os valores percentuais de cada um desses processos na provas de nomeação e imitação do ABFW Teste de Linguagem Infantil ${ }^{33}$.

Inicialmente, foi aplicada a anamnese utilizada como instrumento de rotina no LIF-Fonologia e, em seguida, os pais foram informados sobre a pesquisa e assinaram o Termo de Consentimento Livre e Esclarecido Pós-Informação.

$\mathrm{Na}$ avaliação dos sujeitos foram aplicados todos os testes usados no processo de diagnóstico do LIF Fonologia, entre eles, as provas do ABFW Teste de Linguagem Infantil ${ }^{34}$, as provas do Teste de Sensibilidade Fonológica-Auditivo ${ }^{35}$, as provas de leitura e escrita e as provas de discriminação auditiva. Todas as provas aplicadas foram gravadas em Compact Disc e filmadas com a filmadora digital Sharp VL-E40U utilizando fitas Sony $8 \mathrm{~mm}$ de 120 minutos, à qual foi adaptado um microfone Sony Wireless Professional WM-388.

As sílabas selecionadas para a testagem de ambas as provas foram: la, li, lu; ra, ri, ru e $\Lambda \mathrm{a}, \boldsymbol{\Lambda} \mathrm{i}, \boldsymbol{\Lambda}$. A seleção das vogais que acompanharam as consoantes líquidas foi baseada nos articuladores (lábios e língua) e na posição da língua, ou seja, uma vogal distensa e anterior [i], uma neutra e média [a] e uma arredondada e posterior $[u]$.
Para a realização da avaliação por meio da AA todas as sílabas foram previamente gravadas pela primeira autora deste trabalho em um Compact Disc da marca EMTEC-BASF (CD-R máxima, digital áudio, de 74 minutos) para que a imitação não tivesse o reforço de nenhum modelo articulatório. As amostras de fala foram então apresentadas aos indivíduos por meio de um aparelho de som portátil da marca AKAI (AJ-C010II). Além disso, para o registro das análises, utilizou-se Protocolos de Registro para a Análise Acústica das Consoantes Líquidas Laterais e Vibrantes ${ }^{36}$. As amostras de fala dos dois participantes foram coletadas e armazenadas diretamente no CSL (Computerized Speech Laboratory fabricado pela Kay Elemetrics - modelo 4300B) com a utilização de um microfone unidirecional da marca Shure, modelo SM58. A partir da amostra de fala obtida foram feitas as espectrografias dos sons alvo no próprio CSL.

A prova do IE foi realizada também por meio da imitação de sílabas só que, desta vez, com o sujeito visualizando o modelo articulatório da avaliadora, conforme descrição apresentada abaixo pela segunda autora.

A imitação de sílabas para a AA e para a avaliação do IE foi realizada em dias separados para evitar a interferência da repetição na produção dos sujeitos.

A primeira avaliação realizada foi a de imitação de sílabas previamente gravadas para a AA. Cada sílaba foi apresentada três vezes totalizando 27 repetições para cada um dos sujeitos. As sílabas foram embaralhadas a partir do estímulo alvo, respeitandose as vogais da qual estavam acompanhadas. Foram estabelecidas duas listas diferentes para que pudessem ser excluídas dúvidas em relação ao efeito de aprendizagem das crianças. Na Figura 2 são apresentadas as duas listas apresentadas respectivamente aos sujeitos 1 e $2^{36}$.

Cada sujeito foi posicionado sentado numa cadeira em frente ao computador e ao aparelho de som onde ele ouviu as sílabas que haviam sido previamente gravados, a uma distância média de 10 centímetros do microfone de captação. A examinadora explicou à criança que ela iria ouvir algumas palavras bem pequenininhas e que ela deveria repeti-las. Antes da gravação, foi realizado um treino com três sílabas que, neste momento foram ditas pela própria pesquisadora, através da seguinte ordem: "Repita la, ra e Ka".

Logo após a explicação e a certificação de que a criança havia realmente entendido o que deveria fazer, o aparelho de som foi ligado e o sujeito passou a imitar as sílabas que escutava. Terminada a coleta de cada sujeito, a pesquisadora preenchia o Protocolo de Registro para a Análise Acústica das Consoantes Líquidas Laterais e Vibrantes que foi elaborado para registrar a transcrição fonética dos dados de amostra de fala ${ }^{36}$.

A análise dos dados foi feita a partir da obtenção 
do espectrograma de cada uma das silabas separadamente. Em seguida, utilizando-se da pista auditiva em conjunto com a visual, a examinadora separou o som-alvo da vogal que o acompanhava atentando para que o mínimo das características vocálicas fossem deixadas junto com a consoante devido ao efeito da coarticulação. Desta forma, os valores apresentados nos resultados correspondem exclusivamente aos valores obtidos para a análise do som-alvo, ou seja, dos sons $/ \mathbf{l} / ; / \mathbf{r} / ; / \mathbf{K} /$, previamente separados da vogal. NaAA foram analisados os valores das freqüências formantes $F 1$, F2 e F3 e a duração dos três sonsalvo emitidos nas sílabas pelos dois sujeitos. O valor de cada uma das três repetições foi comparado separadamente para maior fidedignidade da amostra.

Assim como para a AA, a prova do IE também foi composta de 27 sílabas referentes às liquidas [l]; [r]; $[K]$ combinadas com as vogais orais $[a, i, u]$, sendo cada uma delas apresentada três vezes a cada sujeito conforme pode ser observado na Figura $3^{37}$. A ordem de apresentação das sílabas foi sorteada e manteve-se invariável para os dois sujeitos (Figura 3).

Cada sílaba foi produzida uma vez pela examinadora posicionada de frente para o sujeito, para que este pudesse visualizar o modelo articulatório fornecido. Após a emissão da avaliadora, o sujeito foi solicitado a repetir o que havia acabado de escutar.

Os dados das provas do IE foram registrados no momento da coleta e conferidos posteriormente por meio da gravação realizada.

Cada resposta apresentada foi pontuada de 0 (zero) a 2 (dois), sendo 0 (não imitou corretamente), 1 (imitou apresentando distorção) e 2 (imitou corretamente). O total de pontos obtido na prova foi dividido pelo numero total de pontos esperado e multiplicado por 100 , obtendo-se assim, para cada som, um valor referente ao IE daquele sujeito. Além disso, foram analisados os tipos de erros realizados para cada uma das sílabas apresentadas, quanto à ocorrência de omissões, substituições e distorções.

Foi aplicado o Teste t pareado para as comparações entre os formantes dos três sons estudados.

A presente pesquisa foi aprovada pelo Comitê de Ética em Pesquisa da Universidade de São Paulo sob os números 481/01 e 150/03.

\section{RESULTADOS}

Os valores médios das três repetições de F1, F2 e F3 para cada um dos sons-alvo analisados são apresentados na Figura 4.

Na Figura 5 observam-se os resultados que apresentaram diferença estatística significante (Teste $t$ pareado), quando considerada a comparação para cada som-alvo em relação à vogal seguinte para os formantes F1, F2 e F3.
Ressalta-se que a produção do som-alvo [ $K]$ acompanhado da vogal [i] não foi analisada, pois todas as imitações realizadas pelos dois sujeitos foram substituídas pelo som [1], em virtude da proximidade entre os dois sons quando sucedidos pela vogal [i]. Entretanto, esta substituição não foi analisada como uma alteração dentro da figura fonológico dos dois sujeitos, pois a mesma substituição foi previamente observada em estudo anterior realizado com sujeitos normais e com transtorno fonológico ${ }^{37}$.

Como foram observadas diferenças na comparação dos formantes em decorrência da vogal seguinte (Figura 1), em seguida, foi realizada a comparação entre os valores dos três primeiros formantes obtidos a partir da produção dos dois sujeitos, para cada um dos três sons analisados acompanhados de suas respectivas vogais [a], [i], [u].

Não houve diferença estatisticamente significante (Teste t pareado) entre os valores das três primeiras freqüências formantes na comparação entre os dois sujeitos, exceto na imitação da sílaba [ri] somente em relação ao $F 1(p=0.054)$.

A característica acústica de duração do som foi comparada de três maneiras diferentes. A primeira análise, cujos $p$ valores são apresentados na Figura 6 , foi para verificar possíveis diferenças entre a duração dos sons-alvo em relação a vogal seguinte e a segunda, para comparar a duração destes sons entre os dois sujeitos $([1]=p$ 0.360; $[r]=p \quad 0.318 ;[K]=p$ 0.265 ). Nenhuma dessas duas análises apresentou valores estatisticamente significantes, ou seja, as vogais subseqüentes não influenciaram a duração do som-alvo e nem os sujeitos, comparados entre si, apresentaram durações diferentes durante a produção dos sons (Figura 6).

Uma terceira análise, envolvendo o parâmetro da duração comparou a duração do [1] nas sílabas em que ele foi produzido de forma adequada com a duração do som [r] produzido como [1] pelos dois sujeitos em todas as suas produções. Esta análise apresentou diferença estatisticamente significante na aplicação do Teste t pareado $(p=0.016)$.

Devido a esta diferença encontrada na duração do som-alvo [1] produzido de forma adequada e do som [r] substituído por [1], a última análise realizada teve o objetivo de verificar possíveis diferenças entre os valores das freqüências formantes F1, F2 e F3 quando estes dois sons foram comparados. A única significância estatística observada foi em relação ao F1 no contexto em que a vogal [a] foi subseqüente aos dois sonsalvo $(p=0.002)$. Nos outros contextos vocálicos e nas outras freqüências formantes, não foram observadas diferenças estatisticamente significantes (Teste T pareado). 
Na Figura 7, podem ser observados os dados relativos à descrição do Índice de Estimulabilidade (IE) nas imitações dos dois sujeitos para os três sons analisados.

Nota-se que o sujeito 1 foi estimulável para os sons [1] e [ $\Lambda]$, porém não foi estimulável para o [r]. O sujeito 2 foi estimulável para os três sons com maior IE para o som [1], seguido do $[\Lambda]$ e finalmente o [r].

As características de produção dos dois sujeitos, em cada uma das imitações, podem ser observadas na Figura 8 para os sons [1], [r] e [ $K]$ respectivamente.

O sujeito 1 emitiu corretamente o som [1], substituiu o [r], por [l] e o som [ $\boldsymbol{\Lambda}]$ foi adequado para as vogais [a] e [u] e substituído por [1] e [K] quando combinado com a vogal [i]. Em relação às vogais seguintes às líquidas, este sujeito emitiu corretamente o som [1] em todos os contextos, substituiu o [r] na presença das três vogais e emitiu o som $[K]$ de forma adequada quando seguido pelas três vogais da prova, apresentando apenas uma substituição por [y] na emissão do [ $\boldsymbol{\Lambda}]$ seguido pela vogal [a] e uma substituição por [1] quando acompanhado pela vogal [i].

O sujeito 2 também produziu adequadamente o [1]. O som [r] foi produzido de maneira variada, apresentando produção correta em apenas uma das imitações em que estava acompanhado da vogal [a]. Além disso, este som também foi produzido de forma distorcida nas demais imitações com essa vogal, nas três imitações com a vogal [u] e em apenas uma das imitações com a vogal [i] e, substituído por [1] na presença da vogal [i] nas outras duas repetições. O som [ $\boldsymbol{\Lambda}]$, assim como apresentado para o sujeito 1 , foi emitido corretamente na presença da vogal [a] sendo substituído em uma das emissões por [1], emitido de maneira correta nas três emissões com a vogal [u] e, quando acompanhado da vogal [i], apresentou uma emissão correta e as demais substituídas por [1].

Os dois sujeitos produziram adequadamente 0 som [1] nas duas análises (Análise Acústica e Estimulabilidade) realizadas.

Quanto ao som [r] o sujeito 1 não foi estimulável para esse som, tendo substituído-o pelo som [1] independentemente da vogal subseqüente. AAA permitiu verificar que o som [1] foi produzido de maneiras diferentes quando produzido de maneira adequada e quando produzido no lugar do som [r], sendo essa diferença estatisticamente significante para o formante F1 no contexto da vogal /a/. O sujeito 2 foi estimulável ao som [r] e o produziu de forma correta em apenas uma imitação quando acompanhado da vogal /a/. Nas outras imitações com essa vogal foi estimulável, porém produziu o som [r] de forma distorcida. A vogal /i/ mostrou-se o contexto menos facilitador para esse sujeito uma vez que dentre as três emissões realizadas por meio da imitação, duas delas foram produzidas de maneira substituída pelo som [1]. Na AA, durante a visualização do espectrograma, observou-se menor duração e menor presença de ruídos na produção correta deste som quando comparado à produção do mesmo som de maneira distorcida.

Com relação ao som $[\Lambda]$ os dois sujeitos foram estimuláveis de forma semelhante. Ambos produziram corretamente as três emissões apenas quando acompanhadas da vogal/u/. Quando comparados os dados obtidos na AA das produções entre o som $[\Lambda]$ acompanhado da vogal /a/ e da vogal /u/ observou-se diferença estatisticamente significante (Teste t pareado) para o sujeito 1 nos três formantes e para o sujeito 2 no F1.

\begin{tabular}{|c|cc|cc|}
\hline \multicolumn{2}{|c}{ Imitaçăo } & \multicolumn{2}{c|}{ Nomeação } \\
\hline Sujeitos & $\begin{array}{c}\text { Simplificação } \\
\text { de Liquidas }\end{array}$ & $\begin{array}{c}\text { Simplificação } \\
\text { do Encontro } \\
\text { Consonantal }\end{array}$ & $\begin{array}{c}\text { Simplificação } \\
\text { de Liquidas }\end{array}$ & $\begin{array}{c}\text { Simplificação } \\
\text { do Encontro } \\
\text { Consonantal }\end{array}$ \\
\hline 1 & $43,0 \%$ & $58,5 \%$ & $36,0 \%$ & $75 \%$ \\
\hline 2 & $29,0 \%$ & $25,0 \%$ & $27,0 \%$ & $25 \%$ \\
\hline
\end{tabular}

Figura 1 - Porcentagem de processos fonológicos presentes na amostra de fala dos sujeitos nas provas de imitação e nomeação 


\begin{tabular}{|c|c|c|}
\hline \multirow{10}{*}{ Silabas } & Lista 1 & Lista 2 \\
\hline & $1^{a}$. Repetição: [la, ra, אa] & $1^{2}$. Repetiçăo: [la, ra, Ka] \\
\hline & $2^{\mathrm{a}}$. Repetiçāo: [ka, la, ra] & $2^{\mathrm{a}}$, Repetiçāo: [ra, Ka, la] \\
\hline & $3^{8}$. Repetiçäo: $[\mathrm{ra}, \widehat{\Lambda}$, la] & $3^{8}$. Repetiçäo: $[\kappa a$, la, ra] \\
\hline & $4^{\text {a }}$. Repetiçăo: [li, ri, אi] & $4^{a}$. Repetiçăo: [li, ri, si ] \\
\hline & 5a. Repetiçāo: [אi, li, ri] & 5a. Repetiçāo: [ri, אi, li] \\
\hline & 6. Repetiçăo: [ri, $\Lambda \mathrm{i}, \mathrm{li}]$ & 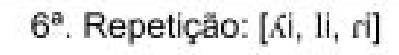 \\
\hline & $7^{\mathrm{a}}$. Repetição: [lu, ru, $K u$ ] & $7^{\mathrm{a}}$. Repetição: [lu, ru, Ku] \\
\hline & $8^{a}$. Repetiçäo: $[\hat{\mathrm{u}}, \mathrm{lu}, \mathrm{ru}]$ & 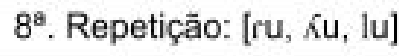 \\
\hline & $9^{\circledR}$. Repetição: [ru, $\kappa u$, lu] & $9^{a}$. Repetiçăo: [Ku, lu, ru] \\
\hline
\end{tabular}

Figura 2 - Lista de sílabas para a imitação e obtenção dos dados para a AA

\begin{tabular}{|c|c|c|}
\hline 1 & r & $\kappa$ \\
\hline la & ru & $\kappa \mathrm{i}$ \\
\hline la & ri & $\kappa \mathrm{u}$ \\
\hline li & ri & $\kappa \mathrm{u}$ \\
\hline la & ra & $\kappa \mathrm{i}$ \\
\hline lu & ru & $\kappa \mathrm{a}$ \\
\hline li & ra & $\kappa \mathrm{i}$ \\
\hline lu & ru & $\kappa \mathrm{a}$ \\
\hline lu & ri & $\kappa \mathrm{u}$ \\
\hline li & ra & \\
\hline
\end{tabular}

Figura 3 - Lista de sílabas para a imitação e obtenção do IE 


\begin{tabular}{|c|c|c|c|}
\hline \multicolumn{2}{|c|}{} & Sujeito $1^{*}$ & ${\text { Sujeito }{ }^{*}}^{*}$ \\
\hline \multirow{3}{*}{$/ 4 /$} & F1 & 344,4 & 347,1 \\
\cline { 2 - 4 } & F2 & 1581,0 & 1578,0 \\
\cline { 2 - 4 } & F3 & 2615,5 & 2637,1 \\
\hline \multirow{3}{*}{$/$ f/ } & F1 & 390,2 & 332,1 \\
\cline { 2 - 4 } & F2 & 1706,8 & 1694,2 \\
\cline { 2 - 4 } & F3 & 2503,7 & 2662,4 \\
\hline \multirow{3}{*}{$/ K /$} & F1 & 311,5 & 305,1 \\
\cline { 2 - 4 } & F2 & 2408,0 & 2100,7 \\
\cline { 2 - 4 } & F3 & 2757,9 & 2795,5 \\
\hline
\end{tabular}

*Valores médios apresentados em $\mathrm{Hz}$

Figura 4 - Valores médios dos formantes F1, F2 e F3 nas três repetições dos sons $/ 1, \mathrm{f}, \mathrm{K} /$

\begin{tabular}{|c|c|c|c|c|}
\hline $\begin{array}{c}\text { Sons } \\
\text { Comparados }\end{array}$ & \multicolumn{2}{|c|}{ Sujeito 1} & \multicolumn{2}{|c|}{ Sujeito 2} \\
\hline la $\times$ li & $F 1(p=0.049)$ & $F 2(p=0.023)$ & $F 1(p=0.018)$ & $F 2(p=0.0003)$ \\
\hline la $\times$ lu & \multicolumn{2}{|c|}{$F 1(p=0.011)$} & \multicolumn{2}{|c|}{$F 1(p=0.005)$} \\
\hline li $x$ lu & \multicolumn{2}{|c|}{$F 2(p=0.031)$} & \multicolumn{2}{|c|}{$\mathrm{F} 2(\mathrm{p}=0.046)$} \\
\hline ra $\times$ ri & \multicolumn{2}{|c|}{$F 1(p=0.032)$} & $F 1(p=0.003)$ & $F 2(p=0.023)$ \\
\hline ra $x$ ru & $F 1(p=0.004)$ & $F 2(p=0.022)$ & - & - \\
\hline rix ru & $\mathrm{F} 2(p=0.026)$ & $\mathrm{F} 3(p=0.040)$ & - & - \\
\hline אa $\times \hat{K u}$ & \multicolumn{2}{|c|}{$F 1(0.043) \quad F 2(0.026) \quad F 3(0.023)$} & \multicolumn{2}{|c|}{ F1 (0.004) } \\
\hline
\end{tabular}

Teste t pareado (nsig $=0,05$ )

Figura 5 - Comparações entre os sons-alvo em relação às vogais seguintes para os formantes F1, F2 e F3

\begin{tabular}{|c|c|c|}
\hline Comparações & Sujeito 1 & Sujeito 2 \\
\hline la $\times$ li & 0.866 & 0.305 \\
\hline la $\times$ lu & 0.087 & 0.440 \\
\hline li $x$ lu & 0.219 & 0.585 \\
\hline ra x ri & 0.240 & 0.882 \\
\hline ra x ru & 0.164 & 0.480 \\
\hline ri x ru & 0.767 & 0.595 \\
\hline Ka $x$ Ku & 0.113 & 0.215 \\
\hline
\end{tabular}

Teste $\mathrm{t}$ pareado $(\mathrm{nsig}=0,05)$

Figura 6 - Comaparação da duração dos sons alvos em relação à vogal seguinte 


\begin{tabular}{|c|c|c|c|}
\hline & Sons & Sujeito 1 & Sujeito 2 \\
\hline \multirow{2}{*}{$\begin{array}{c}\text { Indice de } \\
\text { Estimulabilidade }\end{array}$} & 1 & $100,0 \%$ & $100,0 \%$ \\
\cline { 2 - 4 } & $\mathrm{r}$ & $0,0 \%$ & $44,4 \%$ \\
\cline { 2 - 4 } & $\kappa$ & $77,7 \%$ & $77,7 \%$ \\
\hline
\end{tabular}

Figura 7 - Descrição do IE para os dois sujeitos

\begin{tabular}{|c|c|c|c|c|c|c|}
\hline \multirow[b]{2}{*}{ Estimulo } & \multicolumn{3}{|c|}{ Sujeito 1} & \multicolumn{3}{|c|}{ Sujeito2 } \\
\hline & Produçāo & Tipo de Erro & Pontuaçāo & Produçāo & Tipo de Erro & Pontuaçāo \\
\hline la & la & Correta & 2 & la & Correta & 2 \\
\hline la & la & Correta & 2 & la & Correta & 2 \\
\hline li & li & Correta & 2 & li & Correta & 2 \\
\hline la & la & Correta & 2 & la & Correta & 2 \\
\hline lu & lu & Correta & 2 & lu & Correta & 2 \\
\hline li & li & Correta & 2 & li & Correta & 2 \\
\hline lu & lu & Correta & 2 & lu & Correta & 2 \\
\hline lu & lu & Correta & 2 & lu & Correta & 2 \\
\hline li & li & Correta & 2 & li & Correta & 2 \\
\hline ru & liu & Substituição & 0 & $r^{*} u$ & Distorção & 1 \\
\hline ei & li & Substituiçāo & 0 & li & Substituiçāo & 0 \\
\hline ri & li & Substituiçăo & 0 & li & Substituição & 0 \\
\hline ra & la & Substituiçäo & 0 & ra & Correta & 2 \\
\hline ru & lu & Substituiçāo & 0 & $r^{*} \mathrm{u}$ & Distorçāo & 1 \\
\hline ra & la & Substituiçăo & 0 & $r^{*} a$ & Distorçāo & 1 \\
\hline ru & lu & Substituiçăo & 0 & $r^{*} \mathrm{u}$ & Distorçăo & 1 \\
\hline i & li & Substituiçāo & 0 & $r^{*} i$ & Distorçāo & 1 \\
\hline ra & la & Substituiçăo & 0 & $r^{*} a$ & Distorçăo & 1 \\
\hline Ku & $\hat{~} \mathrm{u}$ & Correta & 2 & ku & Correta & 2 \\
\hline Si & 人i & Correta & 2 & $\Lambda \mathrm{i}$ & Correta & 2 \\
\hline Ku & $\hat{\mathrm{u} u}$ & Correta & 2 & ku & Correta & 2 \\
\hline Ka & אa & Correta & 2 & Ка & Correta & 2 \\
\hline Ku & ku & Correta & 2 & Ku & Correta & 2 \\
\hline $\mathrm{Ki}$ & si & Correta & 2 & Ki & Correta & 2 \\
\hline Ка & אa & Correta & 2 & Ка & Correta & 2 \\
\hline Si & li & Substituiçäo & 0 & li & Substituição & 0 \\
\hline Ka & ia & Substituiçăo & 0 & lia & Substituição & 0 \\
\hline
\end{tabular}

Figura 8 - Descrição dos três sons estudados no IE para os dois sujeitos 


\section{DISCUSSÃO}

Os sujeitos desta pesquisa apresentaram na aplicação do teste de Fonologia o comprometimento dos processos fonológicos de simplificação de liquidas e de encontro consonantal. Este teste já delineou a diferença entre os sujeitos pela diferente produtividade dos processos ${ }^{33}$.

A complementação diagnóstica com o IE e a AA permitiu visualizar especificamente como os sujeitos produzem cada um desses sons. Assim, estas duas análises complementares podem ser utilizadas como instrumentos para que o fonoaudiólogo identifique com maior precisão as alterações e mostre ao sujeito como ele produz cada som (produção alterada) e como este deve ser produzido, possibilitando uma intervenção mais precisa e assertiva ${ }^{21,22,23,27,30}$.

Os sons estudados nesta pesquisa têm características peculiares e podem ser afetados tanto por componentes fonéticos (imprecisões e distorções), quanto por componentes fonológicos (simplificações por omissões ou substituições) ${ }^{38}$.

Conforme observado por meio daAAe da prova que avaliou o IE, os dois sujeitos produziram adequadamente o som [1]. Este resultado corrobora os achados de outros estudos sobre os sons líquidos que relatam que dentre as três líquidas do português brasileiro, o [1] é o que apresenta maior índice de produção correta, sendo em poucas produções distorcido e/ou substituído por outras líquidas ou qualquer outro som ${ }^{36,37}$.

O som $[\Lambda]$ foi emitido corretamente pelos dois sujeitos quando acompanhado das vogais /a/ e /u/; porém quando acompanhado da vogal /i/ foi substituído por [1]. A proximidade dos gestos articulatórios do $[\Lambda]$ e do [i], ou seja, o estreitamento vertical da cavidade oral possibilita uma economia por parte do falante, ocorrendo a transformação do som palatal em palatalizado. Este fato também foi descrito por outros autores que referem que os falantes do português brasileiro geralmente produzem esse som como uma lateral alveolar ou dental palatalizada ${ }^{39}$.

Quando o som $[\Lambda]$ estava acompanhado das vogais /a/ e /u/ o desempenho dos sujeitos foi semeIhante nas duas análises. Em outro estudo houve maior ocorrência de produção correta com as vogais arredondadas [0, $\boldsymbol{\rho}$ e u] que diferiram estatisticamente da vogal [i]. Parece que o gesto articulatório de arredondamento dos lábios facilita a produção deste som, assim como a posição média-alta da língua ${ }^{37}$.

O som [r] foi o que os sujeitos demonstraram maior dificuldade de produção. Analisadas separadamente para cada um dos sujeitos estudados, as produções do som [r] apresentaram uma diferenciação acústica na produção dos sons-alvo para alguns formantes, entretanto, na produção deste som, o sujeito 2 apresentou um menor número de diferenciações (somente para o som /r/ acompanhado da vogal /a/ quando comparado ao mesmo som acompanhado da vogal/i/). Na análise pelo IE este sujeito foi estimulável para o som [r], porém, algumas produções ocorreram com distorção. Outros estudos também evidenciaram a dificuldade de produção desse som ${ }^{8,36,37}$

Embora o sujeito 1 não tenha produzido diferenciações na sua produção que fossem auditivamente perceptíveis durante a prova do IE, a AA permitiu visualizar diferenças na produção do [r] substituído por [1]. Essas diferenças notadas na espectrografia sugerem que o sujeito 1 já tenha percebido a diferença entre o som alvo e o que ele produz, mas que ainda está aprimorando tal produção na medida em que este som exige maior precisão articulatória para ser produzido de maneira correta. Outro estudo demonstrou que o som [r] foi produzido com maior precisão quando seguido das vogais [ $\boldsymbol{\varepsilon}$ e $\boldsymbol{0}$ ], parecendo que a posição média-baixa quanto à altura da língua foi facilitadora para a produção desse som ${ }^{37}$.

Estes dados demonstram que os sujeitos dessa pesquisa ainda não adquiriram o controle motor necessário para a produção adequada do som [r] substituindo-o ou produzindo de forma distorcida e, por isso, desenvolveram estratégias de aproximação ao som alvo. Tais estratégias nem sempre são perceptíveis auditivamente ou visualmente, quando avaliadas pelo teste do IE e nem pela AA de forma isolada. Entretanto, quando analisados em conjunto, os dados obtidos pelos dois testes favorecem a verificação das estratégias utilizadas para a produção do som-alvo. A melhor compreensão dos ajustes feitos pelo sujeito facilita a intervenção fonoaudiológica ${ }^{18,31,32}$.

Outro estudo ${ }^{40}$ também observou maior dificuldade relacionada à líquida lateral palatal e a vibrante, sendo a líquida lateral [1] mais facilmente produzido pelas crianças com ou sem alteração de fala, enquanto a vibrante simples [r] foi o som com maiores dificuldades de produção.

Quando comparados os sujeitos entre si, não foram observadas diferenças na produção dos três sons estudados pela AA (apenas para o F1 na produção da sílaba [ri]) o que reforça a dificuldade de produção deste som independentemente do fato de ser emitida com distorção ou substituição ${ }^{32,38}$.

$\mathrm{Na}$ AA a duração o som-alvo [1] produzido de forma adequada foi diferente da duração do somalvo [r] substituído pelo [1] na imitação das silabas realizadas pelos dois sujeitos. Este dado indica que apesar do som [r] ter sido produzido como [1] pelos dois sujeitos, ambos reconhecem a pista de duração como um fator significativo na sua pro- 
dução demonstrando que são capazes de diferenciar sua produção utilizando-se desta pista acústica. Assim, embora o ouvinte identifique a produção correta e a substituída como um mesmo som há uma diferenciação acústica que os diferencia na produção realizada pelos sujeitos. Embora o sujeito 1 não tenha sido estimulável para esse som, na AA observa-se que ele produz de forma diferenciada a produção correta e a substituída utilizando-se de uma pista acústica (duração) e não das pistas (visual e articulatória) propostas pelo teste do IE. Estudos com a normalidade indicam que o aspecto temporal da fala de crianças atinge valores próximos aos do adulto por volta de 8 anos de idade, sendo que o padrão de freqüência tende a apresentar uma estabilização mais tardia. Isto significa que a duração é um parâmetro muito importante durante o processo de aquisição dos sons e que as informações acústicas trazidas pelas freqüências formantes não oferecem tantas pistas que auxiliem de forma definitiva a aquisição dos mesmos durante este período ${ }^{40}$.

O fato de ser o F1 o único formante a diferenciar a produção correta do [1] e a produção substituída do som [r] pelo [l] somente para a repetição das sílabas formadas pela vogal [a] sugere que esta vogal pode atuar como facilitadora da produção diferenciada destes sons já que também é a primeira vogal a ser adquirida. O F1, por sua vez, é o formante que possui maior amplitude e por isso é considerado o mais forte dentre os três primeiros formantes o que contribui na diferenciação da maneira como os sons são produzidos ${ }^{15}$.

A ausência de omissões pode ser decorrente do fato de que os sujeitos têm o som internalizado em seu sistema fonológico, entretanto não são capazes de produzi-lo de forma adequada, enquanto as distorções do som [r] indicam a dificuldade específica de produção. As substituições sugerem que por não conseguir efetuar a produção correta do som, o sujeito apresenta um sistema fonológico alterado, trocando o som alvo por outro presente em seu inventário fonético e de mais fácil produção, permitindo a efetividade de sua comunicação ${ }^{32,38}$.

A aplicação da Análise Acústica e do Índice de Estimulabilidade pode sugerir ao fonoaudiólogo se o sujeito avaliado tem ou não dificuldade em produzir um som ou, se a sua alteração está somente na organização do sistema fonológico.

O emprego conjunto desses dois procedimentos possibilita ao terapeuta estabelecer os parâmetros facilitadores para a aquisição de um determinado som pelo sujeito, seja ele um parâmetro motor (pistas visuais e articulatórias) ou um parâmetro acústico (freqüência, duração e intensidade). Desta forma, o terapeuta conseguirá reduzir de maneira significativa o período de atendimento além de mostrar ao cliente que sua dificuldade de produção está localizada num determinado parâmetro aumentando assim sua motivação durante o processo terapêutico.

\section{CONCLUSÃO}

A análise proposta permitiu verificar de forma mais detalhada as dificuldades articulatórias dos sujeitos. O IE informa a possibilidade de produção dos diferentes sons, enquanto a AC permite detalhar e elucidar as estratégias utilizadas pela criança unindo os dados articulatórios e acústicos da produção dos sons completando sua descrição.

\begin{abstract}
Purpose: to describe the acoustic characteristics obtained from the acoustic analysis $(A A)$ and the stimulability index $(\mathrm{SI})$ of the liquids $[1] ;[\mathrm{r}] ;[\kappa]$. Methods: we analyzed the speech production elicited by imitation from two twin adolescents aged 11:6 years-old, showing the phonological process of liquid simplification. Their productions were acoustically analyzed before the stimulability test application. Results: the two subjects correctly produced the sound [1]. Subject 1 was not stimulable to the sound [r] and his production was substituted by [1] independently of the subsequent vowel. Subject 2 was stimulable to the sound [r] and produced it correctly only in one of the imitations task when combined with the vowel /a/. The AA showed that the sound [1] was produced in different ways when production was either correct or substituted by [r]. Both subjects were stimulable to $[\Lambda]$. AA showed statistical differences when the $[K]$ was followed by the vowels $/ a /$ and $/ u /$. The vowel /i/ was the only sound that did not facilitate the production of $[K]$ for the subject 2 . Conclusion: the combined use of both procedures was effective in identifying motor and acoustical speech problems and helped to find out some parameters that tend to facilitate the acquisition of a sound.
\end{abstract}

KEYWORDS: Language Disorders; Child Development; Child Language; Speech-Language Pathology 


\section{AGRADECIMENTOS}

Ao CNPq pelo Auxilio à Pesquisa e pelo financiamento de bolsa de mestrado das $2^{\mathrm{a}}$ e $3^{\mathrm{a}}$ autoras.

\section{REFERÊNCIAS}

1. Pagan LO, Wertzner HF. Intervenção no distúrbio fonológico por meio dos pares mínimos com oposição máxima. Pró-Fono. 2002; 14(3):313-24.

2. Klein RP. Acoustic analysis of the acquisition of acceptable $r$ in American English. Child Dev. 1971; 42(2):543-50.

3. Hodson BW, Paden EP. Phonological processes whith characterize unintelligible and intelligible speech in early childhood. J Speech Hear Disord. 1981; 46(3):369-73.

4. Khan LML. Areview of 16 major phonological processes. Lang Speech Hear Serv Sch. 1982; 13(1):77-85.

5. Yavas MS. Padrões na aquisição da fonologia do português. Letras Hoje. 1988; 23(3):7-30.

6. Wertzner HF. Aquisição da articulação: um estudo em crianças de três a sete anos. Est Psicol. 1994; 11:11-21.

7. Goldstein BA, Iglesias A. Phonological patterns in normally developing Spanish-speaking 3 and 4 year olds of Puerto Rican descent. Lang Speech Hear Serv Sch. 1996; 27(1):82-90.

8. Wertzner HF. The typical substitutions of the liquid phonemes in the phonological acquisition of Brazilian children. In: Proceedings of speech pathology Australia National Conference, School of Speech and Hearing Science, and Curtin Printing Services. Australia; Curtin University of Technology: 175-82; 1998.

9. Hernandorena CLM, Lamprecht RR. A aquisição das consoantes líquidas do português. Letras Hoje. 1997; 32(4):7-22.

10. Gurgueira AL. Estudo acústico dos fonemas surdos e sonoros do português do Brasil, em crianças com distúrbio fonológico apresentando o processo fonológico de ensurdecimento. [mestrado]. São Paulo (SP): Universidade de São Paulo; 2000.

11. Wertzner HF, Herrero SF, Ideriha PN, Pires SCF. Classificação do distúrbio fonológico por meio de duas medidas de análise: porcentagem de consoantes corretas (PCC) e índice de ocorrência dos processos fonológicos (PDI). Pró-Fono. 2001; 13(1):90-7.

12. Eguchi S, Hirsh IJ. Development of speech sounds in children. Acta Otolaryngol Suppl. 1969; 257:1-51. 13. Behlau M, Russo I. Percepção da fala: análise acústica do português brasileiro. São Paulo: Lovise; 1993.

14. Behlau M. Voz: o livro do especialista. v. 1. Rio de Janeiro: Revinter; 2001.

15. Kent RD, Read C. The acoustic analysis of speech. 2. ed. San Diego: Singular Publishing Group; 2002. 16. Casaes EJ. Descrição acústico-articulatória dos sons da voz: para um modelo dos sons do português do Brasil. [doutorado]. São Paulo (SP): Universidade de São Paulo; 1990.

17. O'Shaughnessy D. Critique: speech perception: acoustic or articulatory? J Acoust Soc Am. 1996; 99(3):1726-9.

18. Lindblom BE, Sundberg JE. Acoustical consequences of lip, tongue, jaw, and larynx movement. J Acoust Soc Am. 1971; 50(4):1166-79.

19. Farnetani E. Coarticulation and connected speech. In: Hardcastle WJ, Laver J. The handbook of phonetic sciences. Cambridge; Blackwell Publishers; 1997. 20. Powell TW, Miccio AW. Stimulability: a useful clinical tool. J Commun Disord. 1996; 29(4):237-53. 21. Tyler AA. Assessing stimulability in toddlers. J Commun Disord. 1996; 29(4):279-97.

22. Farquhar MS. Prognostic value of imitative and auditory discrimination tests. J Speech Hear Disord. 1961; 26: 342-7.

23. Powell TW, Elbert M, Dinnsen DA. Stimulability as a factor in the phonological generalization of misarticulating preschool children. J Speech Hear Res. 1991; 34(6): 1318-28.

24. Goldstein BA. The role of stimulability in the assessment and treatment of Spanish-speaking children. J Commun Disord. 1996; 29(4):299-314.

25. Lof GL. Factors associated with speech-sound stimulability. J Commun Disord. 1996; 29(4):255-78. 26. Rvachew S, Rafaat S, Martin M. Stimulability, speech perception skills, and the treatment of phonological disorders. Am J Speech Lang Path. 1999; 8:33-43.

27. Miccio AW. Clinical problem solving: assessment of phonological disorders. Am J Speech Lang Path. 2002; 11:221-9.

28. Lowe RJ. Avaliação e intervenção: aplicações na patologia da fala. PortoAlegre:Artes Médicas; 1996. 237 p. 29. Glaspey AM, Stoel-Gammon C. Dynamic assessment in phonological disorders: the scaffolding scale of stimulability. Top Lang Disord. 2005; 25(3):220-30.

30. Rvachew S. Stimulability and treatment success. Top Lang Disord. 2005; 25:207-19.

31. Kent RD. Motor control: neurophysiology and functional development. In: Caruso, A Strand, E. Clinical management of motor speech disorders in children. New York: Thieme Medical Publishers; 1999. 32. Green JR, Moore CA, Reilly KJ. The sequential development of jaw and lip control for speech. J Speech Lang Hear Res. 2002; 45(1):66-79.

33. Wertzner HF. Fonologia. In:Andrade CRF, Befi-Lopes DM, Fernandes FDM, Wertzner HF. ABFW Teste de linguagem infantil nas áreas de fonologia, vocabulário, fluência e pragmática. Carapicuíba: Pró-Fono; 2000.

34. Andrade CRF, Befi-Lopes DM, Fernandes FDM, Wertzner HF. ABFW Teste de linguagem infantil nas áreas de fonologia, vocabulário, fluência e pragmática. Carapicuíba: Pró-Fono; 2000.

35. Herrero SF. Perfil das crianças pré-escolares e es- 
colares no teste de sensibilidade fonológica. [mestrado]. São Paulo (SP): Universidade de São Paulo; 2001.

36. Pagan LO. Estudo das líquidas laterais e vibrantes em crianças com distúrbio fonológico: analise acústica e articulatória. [mestrado]. São Paulo (SP): Universidade de São Paulo; 2003.

37. Castro MM. Estudo da estimulabilidade de crianças com desenvolvimento típico e com distúrbio fonológico para os fonemas líquidos laterais e vibrante simples. [mestrado]. São Paulo (SP): Faculdade de Filosofia Letras e Ciências Humanas da Universi- dade de São Paulo; 2004.

38. Castro MM, Wertzner HF. Estimulabilidade e tipos de erros de fala. Rev Soc Bras Fonoaudiol. 2006; 11(1):1-9.

39. Silva TC. Fonética e fonologia do português: roteiro de estudos e guia de exercícios. São Paulo: Contexto; 2001.

40. Wertzner HF. O distúrbio fonológico em crianças falantes do português: descrição e medidas de severidade. [livre docência]. São Paulo (SP): Universidade de São Paulo; 2002.

RECEBIDO EM: 29/04/2007

ACEITO EM: 18/07/2007

Endereço para correspondência:

Luciana de Oliveira Pagan-Neves

Rua Dr. Nogueira Martins, 400 ap. 52

São Paulo - SP

CEP: 04143-020

Tel: (11) 97381606

E-mail: lucianapagan@hotmail.com 